\title{
Adjuvant Dose-Dense Chemotherapy in Breast Cancer: Standard of Care in High-Risk Patients
}

\author{
Volker Möbus \\ Department of Obstetrics and Gynecology, Clinical Center Frankfurt Höchst, Frankfurt/M., Germany
}

\section{Keywords}

Dose-dense · Adjuvant chemotherapy · Breast cancer

\section{Summary}

Meta-analyses persistently confirm the superiority of dose-dense chemotherapy in comparison with standard chemotherapy. In contrast, individual studies have shown conflicting results. These may be explained by different risk profiles of the treated patient populations. Some trials show a significant advantage in disease-free survival (DFS) and overall survival (OS) in the estrogen receptor (ER)-negative population only, whereas trials with high-risk populations like GIM-2 (Gruppo Italiano Mammella) and AGO-iddETC (Arbeitsgemeinschaft Gynäkologische Onkologie, intense dose-dense epirubicin, paclitaxel, and cyclophosphamide) show a significant superiority in DFS and OS for both, ER-negative and ERpositive patients even after 7 and 10 years, respectively, of follow-up. In contrast, the 10-year follow-up data of the E1199/Intergroup trial no longer showed any superiority of weekly paclitaxel for ER-positive/HER2-negative patients; superiority was observed in the triple-negative subgroup only. Although a direct head-to-head comparison is missing, iddETC or 4 cycles each of dose-dense epirubicin/cyclophosphamide followed by paclitaxel are the preferred adjuvant regimens for patients at risk. Patients with $\geq 4$ positive lymph nodes should preferentially be treated with iddETC.

(c) 2016 S. Karger GmbH, Freiburg

\section{Introduction}

Dose-dense chemotherapy plays a controversial role in the adjuvant treatment of breast cancer patients. Whereas meta-analyses $[1,2]$ persistently describe a significant superiority for dose-dense treatment, the results of large phase III trials remain contradictory [3-9]. Some of these trials showed important differences between the dose-dense and conventional groups regarding number of cycles, type of drug, and total dose. Other trials are accepted and interpreted as dose-dense but present a mixture of dose-dense and conventional schedules [7, 8]. Furthermore, dose-dense and intense dose-dense concepts should be differentiated (fig. 1). Followup duration varies between 3 and 10 years, and the risk profiles of the included patient populations can be remarkably different, thus rendering interpretation of the observed results difficult.

Two very relevant points should be stressed before discussing the trials in detail:

Due to the obligatory use of granulocyte colony-stimulating factor (G-CSF) or pegfilgrastim, treatment-related mortality in all trials is consistently lower in dose-dense regimens in comparison to standard schedules. The rate of myelodysplastic syndrome (MDS) or secondary acute myeloid leukemia (AML) is low and corresponds to standard regimens $[3,6,10]$. Provided that the same regimen is given in the dose-dense and the standard arm, there appears to be no evidence that G-CSF or pegfilgrastim are linked to an elevated risk of MDS or AML $[3,4]$.

\section{Adjuvant Dose-Dense Therapy with G-CSF or Pegfilgrastim Support versus Conventional-Dose Chemotherapy}

Pure Dose-Dense Concepts versus Conventional-Dose Chemotherapy

Four large randomized trials compared adjuvant dose-dense versus conventionally dosed chemotherapy $[3,4,9,11]$. In 2 fur-

\section{KARGER

Prof. Dr. med. Volker Möbus 


\begin{tabular}{|l|l|l|}
\hline Standard dose & $\|$ & \\
$\uparrow$ dose-dense & & \\
$\uparrow$ Intense dose-dense & CALGB 9741, TACT-2 \\
& & \\
NSABP B-38, GIM-2 & $\begin{array}{l}\text { ECOG 1199, } \\
\text { Panther, ETC-trial, } \\
\text { GAIN 1, GAIN 2 }\end{array}$ \\
\hline *Application of G-CSF or Pegfilgrastim is mandatory (only exception ECOG 1199) \\
\hline
\end{tabular}

Fig. 1. Strategies for improving the effectiveness of chemotherapy.

ther trials, the so-called 'dose-dense' arm was a mixture of dosedense and standard-dose chemotherapy, thus hindering an explicit interpretation of the results $[7,8]$.

The first trial, which showed superiority of dose-dense over conventional-dose chemotherapy, was the Cancer and Leukemia Group B (CALGB) trial 9741 [3] demonstrating that a change in the interval of anthracycline- and taxane-based chemotherapy from every 3 weeks ( $\mathrm{q} 3 \mathrm{w}$ ) to every 2 weeks (q2w) significantly improved disease-free survival (DFS) (hazard ratio (HR) 0.74; $\mathrm{p}=$ $0.010)$ and overall survival (OS) (HR 0.69; $\mathrm{p}=0.013)$ in women with lymph node-positive early-stage breast cancer.

The findings of the recently published GIM-II trial [4] from Italy support the results of CALGB 9741. 2,091 patients were randomized to 1 of 4 study groups: 4 cycles of epirubicin (E) / cyclophosphamide (C) $\left(90 / 600 \mathrm{mg} / \mathrm{m}^{2}\right)$, followed by 4 cycles of paclitaxel (P) 175 $\mathrm{mg} / \mathrm{m}^{2}$, given either at 2-week (dose-dense) or 3-week intervals (conventional-dose) plus/minus 5-fluorouracil (5-FU) in addition to EC (FEC). The addition of 5-FU had no impact on DFS and OS, but 5 -year DFS (HR 0.77; p = 0.004) and OS rates (HR 0.65; p = 0.001 ) were significantly better in the dose-dense group. 5 -year OS was $94 \%$ in the dose-dense arm versus $89 \%$ in the standard arm. However, both trials had a standard arm (4 cycles of doxorubicin/ cyclophosphamide (AC)/EC followed by 4 cycles of paclitaxel $\mathrm{q} 3 \mathrm{w}$ ) which probably no longer reflects today's standard of care.

Four trials did not show superiority of the dose-dense schedule over conventional-dose chemotherapy [7-9, 11]. At first glance, this constellation does not appear to support the superiority of dose-dense chemotherapy. However, can these conflicting results be explained?

The GONO-MIG (Gruppo Oncologico Nord Ovest-Mammella InterGruppo) trial [11] compared FEC q3w versus the same regimen given $\mathrm{q} 2 \mathrm{w}$. The difference between these $2 \mathrm{arms}$ did not reach statistical significance for either recurrence (HR 0.88; $\mathrm{p}=0.22$ ) or death (HR 0.87; $\mathrm{p}=0.29$ ). These negative results may be explained by the study design. The GONO-MIG trial applied a substandard version of the FEC regimen (i.e., $5-\mathrm{FU}$ at $600 \mathrm{mg} / \mathrm{m}^{2}$, epirubicin at $60 \mathrm{mg} / \mathrm{m}^{2}$, and cyclophosphamide at $600 \mathrm{mg} / \mathrm{m}^{2}$ for 6 cycles). The total dose of epirubicin in both arms was $360 \mathrm{mg} / \mathrm{m}^{2}$, which corresponded to only $50 \%$ of the total dose in the highly effective Canadian CEF regimen [10].
Results from the UK TACT2 (United Kingdom Trial of Accelerated ChemoTherapy) trial have so far been published in abstract form only [7], and the regimens used in the Canadian MA-21 trial [8] were only in part dose-dense. The TACT2 trial compared 4 cycles of epirubicin $\mathrm{q} 3 \mathrm{w}$ versus $\mathrm{q} 2 \mathrm{w}$, followed by standard chemotherapy with either CMF (cyclophosphamide, methotrexate, 5-FU) or capecitabine, and showed no difference in 5-year event-free survival (HR 0.96; $\mathrm{p}=0.60$ ) or OS (HR 1.13; $\mathrm{p}=0.23$ ).

The 3-arm Canadian MA-21 trial [8] had only a short followup duration of 30 months. Patients in the intense 'dose-dense' arm received 6 cycles of epirubicin $120 \mathrm{mg} / \mathrm{m}^{2}$ and cyclophosphamide $830 \mathrm{mg} / \mathrm{m}^{2} \mathrm{q} 2 \mathrm{w}$ followed by 4 standard courses of paclitaxel 175 $\mathrm{mg} / \mathrm{m}^{2} \mathrm{q} 3 \mathrm{w}(\mathrm{EC} \diamond \mathrm{T})$. Similar to the UK TACT2 trial, the 'dosedense' arm again represents a mixture of dose-dense and standard schedules. The 'dose-dense' arm was randomized against 2 standard regimens, i.e. Canadian $\mathrm{CEF}$ or $\mathrm{AC} \times 4$ followed by paclitaxel $\times 4(\mathrm{AC} \vee \mathrm{T})$. The results of the Canadian trial showed that $\mathrm{AC} \vee \mathrm{T}$ was inferior to both CEF and intense dose-dense EC $\diamond \mathrm{T}$. The authors reported no difference in DFS between CEF and intense dose-dense EC $\diamond \mathrm{T}$ (HR 0.89; $\mathrm{p}=0.46)$. There are several possible explanations for these results. The total planned cumulative dose, dose intensity, and duration of anthracyline treatment were greater in $\mathrm{EC} \diamond \mathrm{T}$ and CEF in comparison to $\mathrm{AC} \diamond \mathrm{T}$. In the $\mathrm{EC} \diamond \mathrm{T}$ and $\mathrm{AC} \diamond \mathrm{T}$ arms, the taxane dose and schedule were the same. Again, the total planned cumulative dose and the dose density were greater in $\mathrm{EC} \diamond \mathrm{T}$.

The NSABP B-38 trial [9] was a 3-arm study which compared 4 cycles of dose-dense doxorubicin and cyclophosphamide followed by 4 cycles of dose-dense paclitaxel (dose-dense AC $\diamond \mathrm{P}$ ) or the same regimen with 4 cycles of gemcitabine $(G)$ added to paclitaxel (dosedense $\mathrm{AC} \triangleright \mathrm{PG}$ ) or 6 cycles of docetaxel, doxorubicin, and cyclophosphamide (TAC) q3w. In this large study with nearly 5,000 randomized patients, the addition of gemcitabine to dose-dense AC $\triangle \mathrm{P}$ did not improve outcomes. In addition, no significant differences in efficacy end points were identified between the investigational arm dose-dense AC $\diamond \mathrm{PG}$ and TAC (5-year DFS: HR 0.93; $\mathrm{p}=0.39$; 5-year OS: HR 0.86; $\mathrm{p}=0.17$ ).

\section{Intense Dose-Dense Concepts versus Conventional-Dose Chemotherapy}

The importance of dose intensity for adjuvant chemotherapy in patients with breast cancer was first described by Hryniuk as early as 1986 [12]. Higher dose intensity can be achieved by either increasing the single dose per cycle (i.e., higher dose) and/ or by reducing the intervals between cycles (i.e., higher dose density).

In contrast to CALGB 9741 and GIM II, which were purely based on the concepts of dose density and sequential application with the total dose of each agents identical in both arms, the intense dose-dense regimen of epirubicin $150 \mathrm{mg} / \mathrm{m}^{2} \mathrm{q} 2 \mathrm{w} \times 3$, paclitaxel $225 \mathrm{mg} / \mathrm{m}^{2} \mathrm{q} 2 \mathrm{w} \times 3$, and cyclophosphamide $2,500 \mathrm{mg} / \mathrm{m}^{2} \mathrm{q} 2 \mathrm{~W}$ $\times 3$ (iddETC) was dose-dense and used a higher total dose per cycle [6]. The control arm with 4 cycles EC (AC) followed by 4 cycles of paclitaxel is identical to CALGB 9741 and GIM II. 


\begin{tabular}{|c|c|c|c|c|c|}
\hline & TACT 2 & NSABP B-38 & CALGB 9741 & GIM-2 & AGO-iddETC \\
\hline & 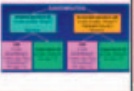 & 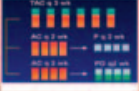 & 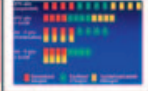 & 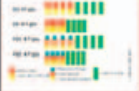 & 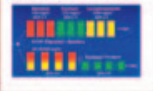 \\
\hline n & 4391 & 4894 & 2005 & 2091 & 1284 \\
\hline schedule & $\begin{array}{c}\text { dose-dense } \\
(\mathrm{q} 2 \mathrm{w})\end{array}$ & $\begin{array}{l}\text { dose-dense } \\
\text { (q2w) }\end{array}$ & $\begin{array}{l}\text { dose-dense } \\
\text { (q2w) }\end{array}$ & $\begin{array}{c}\text { dose-dense } \\
\text { (q2w) }\end{array}$ & $\begin{array}{l}\text { dose-dense } \\
\text { (q2w) and dose- } \\
\text { intensified }\end{array}$ \\
\hline $\begin{array}{l}\text { inclusion } \\
\text { criteria }\end{array}$ & $\begin{array}{l}\text { NO (high- } \\
\text { risk), N+ }\end{array}$ & $\mathrm{N}+$ & $\mathrm{N}+$ & $\mathrm{N}+$ & $\geq 4 \mathrm{LN}+$ \\
\hline No & $46.8 \%$ & $0 \%$ & $0 \%$ & $0 \%$ & $0 \%$ \\
\hline $1-3 \mathrm{LN}+$ & $40.5 \%$ & $65 \%$ & $59 \%$ & $16.4 \%$ & $0 \%$ \\
\hline $4-9 \mathrm{LN}+$ & \multirow{2}{*}{$12.6 \%$} & $25 \%$ & $29 \%$ & $30.7 \%$ & $58 \%$ \\
\hline$\geq 10 \mathrm{LN}+$ & & $10 \%$ & $12 \%$ & $48 \%$ & $42 \%$ \\
\hline$\underset{+}{\text { median LN }}$ & $N=1$ & $N=2$ & $N=3$ & $N=5$ & $N=8$ \\
\hline
\end{tabular}

Fig. 2. Risk profile of dose-dense trials.

The iddETC trial recruited only high-risk patients with $\geq 4$ positive lymph nodes and is the only trial which reports long-term survival data [5]. With 10 years of follow-up, event-free survival was significantly longer for the iddETC arm with 56 vs. $47 \%$ and a HR of 0.74 . The relative risk of mortality was reduced by $28 \%$ (HR 0.72 ; log rank test $\mathrm{p}=0.0007)$. Given the fact that $42 \%$ of the patients had $\geq 10$ positive nodes with a median number of 8 positive nodes, the 10 -year survival rate of $69 \%$ in the iddETC arm represents to the best of our knowledge the highest survival rate reported for such a high-risk group of patients to date.

Comparison of (Intense) Dose-Dense versus Conventional-Dose Chemotherapy - Why Do We Have Positive and Negative Trials?

A central reason for the conflicting results reported by trials comparing (intense) dose-dense versus standard regimens is likely to be the differences in the risk profile of the studied patient populations (fig. 2). CALGB 9741, GIM-2, and iddETC have shown superiority of (intense) dose-dense regimens. In contrast, UK TACT 2 and NSABP B-38 failed to show superiority of dose-dense regimens. We cannot exclude that the TAC regimen used in the NSABP B-38 trial may be a more effective standard regimen in comparison to AC (EC) followed by paclitaxel which was the standard regimen in the CALGB 9741, GIM-2, and AGO-iddETC trials. A second probable explanation for the contradictory results is the completely different risk profile of the patient populations in the negative and the positive trials.

Whereas the UK TACT 2 trial consists to $87.3 \%$ of patients with node-negative or N1 disease, none of these low-risk patients have been recruited by the AGO-iddETC trial. The median number of positive nodes is 1 in the UK TACT 2 trial and 8 in AGO iddETC. Consistently, the risk profile of the negative NSABP B-38 trial is also very low with $65 \%$ of patients with only $1-3$ positive nodes and a median number of 2 positive nodes. Again, no patients with 1-3 positive lymph nodes have been recruited by the iddETC trial. In addition, no human epidermal growth factor receptor 2 (HER2)-overexpressing patients were recruited in NSABP B-38. Consistently, only trials which recruited patients with a high-risk profile have shown superiority of (intense) dose-dense regimens.

\begin{tabular}{|c|c|c|c|c|}
\hline & 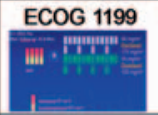 & $\begin{array}{c}\text { CALGB } 9741 \\
\\
\end{array}$ & 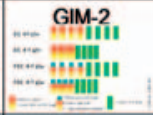 & $\begin{array}{l}\text { AGO-iddETC } \\
\frac{11}{2+18} \\
\end{array}$ \\
\hline$n$ & 4950 & 2005 & 2091 & 1284 \\
\hline schedule & $\begin{array}{l}\text { dose-dense } \\
(q 1 w) \text { and dose- } \\
\text { intensified }\end{array}$ & $\begin{array}{l}\text { dose-dense } \\
\text { (q2w) }\end{array}$ & $\begin{array}{l}\text { dose-dense } \\
\text { (q2w) }\end{array}$ & $\begin{array}{l}\text { dose-dense (q2w) } \\
\text { and dose-intensified }\end{array}$ \\
\hline $\begin{array}{c}\text { inclusion } \\
\text { criteria }\end{array}$ & $\begin{array}{c}\text { No (high-risk), } \\
\mathrm{N}+\end{array}$ & $\mathrm{N}+$ & $\mathrm{N}+$ & $\geq 4 \mathrm{LN}+$ \\
\hline $\begin{array}{c}\text { OS benefit ER+ } \\
\text { pat. }\end{array}$ & no & no & yes & yes \\
\hline $0-3 \mathrm{LN}+$ & $68 \%$ & $59 \%$ & $18 \%$ & $0 \%$ \\
\hline 4-9 LN + & $22 \%$ & $29 \%$ & $32 \%$ & $58 \%$ \\
\hline$\geq 10 \mathrm{LN}+$ & $10 \%$ & $12 \%$ & $48 \%$ & $42 \%$ \\
\hline Median LN + & $N=1$ & $N=3$ & $N=5$ & $N=8$ \\
\hline
\end{tabular}

Fig. 3. Dose-dense trials: effectiveness dependent on estrogen receptor status.

This observation is valid even inside a trial population. In the iddETC trial, patients with $\geq 10$ positive lymph nodes showed a higher reduction in mortality compared to patients with 4-9 positive nodes. The same was noted in the GIM-2 trial. Only patients with 4 and more positive nodes had a significant reduction in DFS and OS with dose-dense treatment.

We conclude that the predominant part of the patients recruited by TACT 2 and NSABP B-38 belong to the low- or intermediaterisk group. With the use of new prognostic factors like Ki-67 for the differentiation between luminal A and luminal B or commercial multigene assays like Oncotype DX ${ }^{\circledR}$ (Genomic Health, Redwood City, CA, USA), EndoPredict ${ }^{\circledR}$ (Myriad Genetics, Salt Lake City, UT, USA), Prosigna ${ }^{\circledR}$ (NanoString Technologies, Seattle, WA, USA), or MammaPrint ${ }^{\circledR}$ (Agendia, Irvine, CA, USA), a bigger part of these patients would not be treated with chemotherapy according to current knowledge. If a patient is not a candidate for chemotherapy, according to his/her risk profile, we would not expect to see any difference between the effects of an established standard or an intense dose-dense regimen.

This hypothesis is emphasized by the fact that (intense) dosedense chemotherapy was effective in hormone receptor-positive patients only in the GIM-2 and AGO-iddETC trials but not in CALGB B9741 (fig. 3). A high-risk situation may effectively erase the (intense) dose-dense and HER2/estrogen receptor (ER) interaction.

Dose-Dense Concepts without G-CSF Support (Weekly Schedule) versus Standard-Dose Chemotherapy

The ECOG 1199/Intergroup trial compared the efficacy of 2 different taxanes, docetaxel and paclitaxel, given either $\mathrm{q} 3 \mathrm{w}$ or weekly, in the adjuvant treatment of breast cancer patients. In the 5-year analysis [13], the group receiving 4 cycles of AC followed by 12 weekly cycles of paclitaxel $80 \mathrm{mg} / \mathrm{m}^{2}$ showed significantly improved DFS (HR 1.27; $\mathrm{p}=0.006)$ and OS (HR 1.32; $\mathrm{p}=0.01$ ) as compared to patients receiving the former standard of paclitaxel $175 \mathrm{mg} / \mathrm{m}^{2} \mathrm{q} 3 \mathrm{w}$. Especially patients with HER2-negative disease who received weekly paclitaxel had improved DFS (HR 1.33; $\mathrm{p}=$ 0.009 ) and OS (HR 1.34; $\mathrm{p}=0.03$ ), irrespective of their hormone receptor status. 
As a consequence of this and other studies [14, 15], weekly paclitaxel became a preferred standard regimen, especially given sequentially after 4 cycles of AC. Doxorubicin $60 \mathrm{mg} / \mathrm{m}^{2}$ can be substituted with epirubicin $90 \mathrm{mg} / \mathrm{m}^{2}$ [16].

It is important to note that weekly paclitaxel $80 \mathrm{mg} / \mathrm{m}^{2}$ is not only dose-dense, but it represents an intense dose-dense schedule. 3-weekly cycles amount to a total dose of $240 \mathrm{mg} / \mathrm{m}^{2}$, which leads to a higher total dose and dose intensity in comparison with paclitaxel $175 \mathrm{mg} / \mathrm{m}^{2} \mathrm{q} 3 \mathrm{w}$.

Recently, long-term outcome data were reported [17]. When compared with the standard paclitaxel $\mathrm{q} 3 \mathrm{w}$ arm, after a median follow-up of 12.1 years, only DFS (HR 0.84; $\mathrm{p}=0.01$ ) but no longer OS (HR 0.87; $\mathrm{p}=0.09$ ) was statistically different between the weekly paclitaxel arm and the docetaxel q3w arm (HR 0.79; p = 0.001 and HR.86; $\mathrm{p}=0.054$ ). Clinical outcome and response may vary depending on the breast cancer subtype. For the 2,879 patients with ER-positive/HER2-negative disease, docetaxel q3w was associated with improved DFS (HR 0.76; $p=0.004$ ) but not OS. For the paclitaxel weekly arm, no significant results were observed for either DFS or OS after 12 years of follow-up.

The new analysis also revealed that only paclitaxel weekly was associated with an approximately $30 \%$ reduction in the risk of recurrence and death in the triple-negative subtype. Weekly paclitaxel may become a preferred regimen for triple-negative breast cancer.

\section{Do We Know the Optimal Schedule of Dose-Dense \\ Chemotherapy?}

The SWOG SO221 [18] trial had an open-label $2 \times 2$ factorial design to test 2 hypotheses: i) 6 cycles of AC $\left(60 / 600 \mathrm{mg} / \mathrm{m}^{2}\right) \mathrm{q} 2 \mathrm{w}$ versus a novel continuous schedule of intravenous doxorubicin 24 $\mathrm{mg} / \mathrm{m}^{2}$ once per week, cyclophosphamide $60 \mathrm{mg} / \mathrm{m}^{2}$ orally once per day for 15 weeks, supported either by pegfilgrastim or filgrastim; and ii) paclitaxel $80 \mathrm{mg} / \mathrm{m}^{2}$ once weekly is superior to 6 cycles of paclitaxel $175 \mathrm{mg} / \mathrm{m}^{2} \mathrm{q} 2 \mathrm{w}$.

At a median follow-up of 6 years, an interaction between the 2 randomized factors had emerged so that the 2 randomizations could not be analyzed independently. For the comparison of $6 \mathrm{cy}-$ cles AC q2w followed by 6 cycles paclitaxel q2w versus 6 cycles AC $\mathrm{q} 2 \mathrm{w}$ followed by 12 cycles paclitaxel weekly, the authors reported a trend in DFS (HR 1.24; $\mathrm{p}=0.072$ ) and a significant difference in OS (HR 1.46; $\mathrm{p}=0.01$ ) favoring patients who received all treatments $\mathrm{q} 2 \mathrm{w}$. Examination of relevant biologic subsets reveals that this advantage for treatment $\mathrm{q} 2 \mathrm{w}$ is observed only in patients with hormone receptor-/HER2-negative disease. This observation is the result of a subset analysis that was not protocol-specified and should be regarded as hypothesis-generating.

It must be noted that 6 cycles of paclitaxel $\mathrm{q} 2 \mathrm{w}$ were given, rather than the 4 cycles commonly used. This means that no direct comparison can be drawn between 12 weeks of once-weekly paclitaxel and 4 cycles of q2w treatment. Clinically relevant toxic effects, such as allergic-type reactions, musculoskeletal pain, and neuropathy, are more common with the $\mathrm{q} 2 \mathrm{w}$ schedule [18].
To what extent the dose-dense application of AC (EC) contributes to the superior efficacy observed in the GIM-2 and CALGB 9741 studies [3] also remains an open question because no study has compared AC (EC) q2w with AC (EC) q3w, followed by weekly paclitaxel in both groups.

A direct comparison between iddETC and 8 cycles of dosedense $\mathrm{AC} \vee \mathrm{P}$ [3] or $\mathrm{AC} \mathrm{q} 3 \mathrm{w} \times 4$ followed by weekly paclitaxel $\times 12$ is also missing.

Considering the results of iddETC, one should be aware that dose intensity may also play a role in optimizing the effectiveness of dose-dense regimens.

\section{Phase III Trials Comparing Different Dose-Dense Concepts}

Three randomized phase III trials have compared different dose-dense regimens. All 3 trials incorporated a 4 th cytostatic compound in their experimental arm. The NSABP B-38 trial [9] and the GIM-2 trial [4] intended to improve the dose-dense standard regimen, $\mathrm{AC}(\mathrm{EC}) \mathrm{q} 2 \mathrm{w} \times 4$ followed by paclitaxel $\mathrm{q} 2 \mathrm{w} \times 4$ [3]. While NSABP B-38 performed a subrandomization of $+/$ - gemcitabine, the GIM-2 trial evaluated 5-FU as a 4 th compound. The GAIN trial intended to improve the results of iddETC by incorporating capecitabine as a 4 th cytostatic compound [19]. iddETC was randomized against 4 cycles of EC followed by 10 cycles of paclitaxel weekly in combination with 4 cycles of capecitabine 2,000 $\mathrm{mg} / \mathrm{m}^{2}$ days $1-14 \times 4$. The total doses of epirubicin and paclitaxel were identical in both arms, whereas the dosage of cyclophosphamide was lower in the experimental arm.

Hematological and nonhematological toxicity was higher with the 4-drug dose-dense regimens. However, all 3 trials failed to improve the effectiveness of the established (intense) dose-dense 3 -drug regimens by incorporating one of these compounds. Hence, 3-drug dose-dense regimens remain the standard of care.

\section{Conclusion}

Dose-dense chemotherapy should be the standard of care in high-risk breast cancer patients. Dose-dense regimens with 4 drugs have not shown superiority over 3-drug regimens. The importance of total dose in addition to a purely dose-dense concept remains an open question.

\section{Disclosure Statement}

V.M. received honoraria from AMGEN, Celgene, and Roche and has an advisory role with Celgene. 


\section{References}

1 Bonilla L, Ben-Aharon I, Vidal L, et al.: Dose-dense chemotherapy in nonmetastatic breast cancer: a systematic review and meta-analysis of randomized controlled trials. J Natl Cancer Inst 2010;102:1845-1854.

2 Petrelli F, Cabiddu M, Coinu A, et al.: Adjuvant dosedense chemotherapy in breast cancer: a systematic review and meta-analysis of randomized trials. Breas Cancer Res Treat 2015;151:251-259.

3 Citron ML, Berry DA, Cirrincione C, et al.: Ran domized trial of dose-dense versus conventionally scheduled and sequential versus concurrent combination chemotherapy as postoperative adjuvant treatment of node-positive primary breast cancer: first report of intergroup trial C9741/Cancer and Leukemia Group B Trial 9741. J Clin Oncol 2003;21:1431-1439.

4 Del Mastro L, de Placido S, Bruzzi P, et al.: Fluorouracil and dose-dense chemotherapy in adjuvant treatment of patients with early-stage breast cancer: an open-label, $2 \times 2$ factorial, randomized phase 3 trial. Lancet 2015;385:1863-1872.

5 Moebus V, Jackisch C, Lueck HJ, et al.: Ten-year follow-up analysis of intense dose-dense adjuvant ETC (epirubicin (E), paclitaxel (T) and cyclophosphamide (C) confirms superior DFS and OS benefit in comparison to conventional dosed chemotherapy in high-risk breast cancer patients with $\geq 4$ positive lymph nodes. SABCS 2012;abstr S3-04.

6 Moebus VJ, Jackisch C, Lueck HJ, et al.: Intense dosedense chemotherapy with epirubicin, paclitaxel and cyclophosphamide compared with conventionally scheduled chemotherapy in high-risk primary breast cancer: mature results of an AGO phase III study. J Clin Oncol 2010;28:2874-2880.
Cameron D, Barrett-Lee P, Canney P, et al.: The UK TACT2 Trial: comparison of standard vs. accelerated epirubicin in patients requiring chemotherapy for early breast cancer. SABCS 2012; abstr S3-3.

8 Burnell M, Levine MN, Chapman JW, et al.: Cyclophosphamide, epirubicin, and fluorouracil versus dose-dense epirubicin and cyclophosphamide followed by paclitaxel versus doxorubicin and cyclophosphamide followed by paclitaxel in node-positive or highrisk node-negative breast cancer. J Clin Oncol 2009;28: 77-82.

9 Swain S, Tang G, Geyer C, et al.: Definitive results of a phase III adjuvant trial comparing three chemotherapy regimens in women with operable, node-positive breast cancer: the NSABP B-38 Trial. J Clin Oncol 2013;31:3197-3204

10 Levine M, Pritchard K, Bramwell V, et al.: Randomized trial comparing cyclophosphamide, epirubicin, and fluorouracil with cyclophosphamide, methotrexate, and fluorouracil in premenopausal women with nodepositive breast cancer: update of National Cancer Institute of Canada Clinical Trials Group Trial MA5. J Clin Oncol 2005;23:5166-5170.

11 Venturini M, Del Mastro L, Aitini E, et al.: Dose-dense adjuvant chemotherapy in early breast cancer patients: results from a randomized trial. J Natl Cancer Inst 2005;97:1724-1733.

12 Hryniuk W, Levine MN: Analysis of dose intensity for adjuvant chemotherapy trials in stage II breast cancer. J Clin Oncol 1986;4:1162-1170.

13 Sparano JA, Wang M, Martino S, et al.: Weekly paclitaxel in the adjuvant treatment of breast cancer. $\mathrm{N}$ Engl J Med 2008;358:1663-1671.
4 Martin M, Rodriguez-Lescure A, Ruiz A, et al.: Randomized phase 3 trial of fluorouracil, epirubicin, and cyclophosphamide alone or followed by paclitaxel for early breast cancer. J Natl Cancer Inst 2008;100:805814.

5 Martin M, Ruiz A, Ruiz Borrego M, et al.: Flourouracil, doxorubicin, and cyclophosphamide (FAC) versus FAC followed by weekly paclitaxel as adjuvant therapy for high-risk, node-negative breast cancer: results from the GEICAM/2003-02 study. J Clin Oncol 2013;31: 2593-2599.

16 AGO Therapieempfehlungen der Kommission Mamma, Version 2015.1. www.ago-online.de.

17 Sparano JA, Zhao F, Martino S, et al.: Long-term follow-up of the E1199 phase III trial evaluating the role of taxane and schedule in operable breast cancer. J Clin Oncol 2015;33:2353-2360.

18 Budd GT, Barlow WE, Moore HCF, et al.: SWOG S0221: a phase III trial comparing chemotherapy schedules in high-risk early-stage breast cancer. J Clin Oncol 2015;33:58-64

19 Moebus VJ, von Minckwitz G, Jackisch C, et al.: German Adjuvant Intergroup Node Positive (GAIN) study: a phase III trial to compare IDD-ETC versus EC-TX in patients with node-positive primary breast cancer - final efficacy analysis. J Clin Oncol 2014; 32(suppl 5s):abstr 1009 